\title{
IDENTIFYING THE FACTORS AFFECTING FINANCIAL CONDITION OF MALAYSIA
}

\author{
Yee-Ling Pang \\ Universiti Malaysia Sabah \\ Hock-Ann Lee * \\ Universiti Malaysia Sabah
}

\begin{abstract}
This research focuses on the domestic and external determinants of Malaysia's financial condition, ranging from January 2003 and March 2019. To represent the domestic determinants, a total amount of twelve financial indicators are adopted to compute three indices using the Principal Component Approach (PCA). Three of the indices embody three respective financial segments, particularly the banking system, the foreign exchange market, and the capital market within the Malaysian financial system. These three segments offer a glimpse of the Malaysian financial condition. For the external determinant, the US total assets of all Federal Reserve Banks are adopted as the proxy for the size of the US balance sheet. This research intends to evaluate the validity of the long-run association and its corresponding level of effect between the computed indices and the US balance sheet size via the conduct of the ARDL bounds test approach. The research findings have verified the validity of the long-run association between the Malaysian financial condition and the US balance sheet size. There is a substantial role played by the US balance sheet size in affecting the well-being of Malaysian financial condition, given the statistical significance is shown in the association between the US balance sheet size and the financial-segment-based indices, whereby its strongest influence is found on the banking system condition.
\end{abstract}

Keywords: Financial Condition; Unconventional Monetary Policy; US Balance Sheet; Malaysia.

Received: 13 January 2020

Accepted: 30 December 2020

https://doi.org/10.33736/ijbs.3185.2021

\section{INTRODUCTION}

Financial disruption destabilizes the financial market condition, transitioning into the economic downturn. In the late 2000s, the Global Financial Crisis (GFC) originating from the United States (US) has caused a global-scale recession. Such turbulence contracted household consumption and national employment, also paralyzed the financial markets, and the price stability in the US and the rest of the world in the globalization era. To revamp the US economy, the US authority repeatedly altered the conventional monetary policy (CMP) tool, i.e fed funds rate. The rate shrank continuously till it reached the zero lower bound (ZLB) during the last quarter of 2008 (Borio \& Zabai, 2018). At ZLB, the CMP tool lost its effectiveness. Therefore, the US policymakers

\footnotetext{
- Corresponding author: Labuan Faculty of International Finance, Universiti Malaysia Sabah Labuan International Campus, Jalan Sungai Pagar, 87000 Labuan Federal Territory, Labuan Federal Territory, Malaysia; Tel: +6087-503000; Ext 410002; Email: hockann@ums.edu.my.
} 
proceeded to develop alternative monetary measures for economic stabilization. Thus, the unconventional monetary policy (UMP) measures i.e. the Quantitative Easing (QE) plans which include a series of asset purchases at large scale (LSAPs) were introduced by the Fed starting from November 2008, to adjust the long-term interest rates (Neely \& Bhattarai, 2016). Eventually, studies have mushroomed to examine the influence of US UMP measures both on the US and the rest of the economies, i.e. small developed nations and developing regions (Chen, Filardo, He, \& Zhu, 2016; Hofmann \& Takats, 2015; Punzi \& Chantapacdepong, 2017). The literature majorly revolves around the theme of US policy rates' alteration and LSAPs announcements, while lesser on the theme of the LSAPs' actual operation (Bauer \& Neely, 2014; Borio \& Zabai, 2018; Neely \& Bhattarai, 2016).

US's implementation of the unconventional monetary policy escalated the financial volatility in the global market. The spillover impacts were evident in both the advanced economies (AEs) and the emerging market economies (EMEs) (Hofmann \& Takats, 2015). To curb the damage stemming from GFC, the international businesses of the AEs have withdrawn the trades with their trade partners, including Malaysia, an export-dependent EME (Lim \& Goh, 2010). The event induced a plummet in capital inflows starting from Q2 2008, followed by fragile export growth in the Q4 2008. Equity prices plunged, hurting the economic and financial environment in Malaysia (Tey, Baharudin, \& Fuad, 2018). In 2009, Malaysia was paved into its fully-developed economic slump. Consequently, Malaysia relieved the situation with a series of fiscal and accommodative monetary stimulus plans (Tey et al., 2018).

The financial episode also enlightened the importance of a sound financial condition. The financial condition serves as an intermediary agent between the transmission of monetary policy (MP) alteration and macroeconomic behavior (Hatzius, Hooper, Mishkin, Schoenholtz, \& Watson, 2010). Over the decades, the growing complexity of the financial system urges the global policymakers to view the financial condition with a broader perspective to refine monetary conduct (Badrudin \& Abu Bakar, 2017). The Financial Condition Index (FCI) earns its prominence by providing a glance at the overall financial circumstances. The index takes an extensive array of financial variables from respective financial components within the system into account (Angelopoulou, Balfoussia, \& Gibson, 2014; Debuque-Gonzales \& Gochoco-Bautista, 2013, 2017; Hatzius et al., 2010). Given most studies are established on providing a summary indicator to inform on the general financial condition, hence viewing financial condition by the perspective of included financial components is still novel.

This research engages in the domestic and external determinants that influence the Malaysian financial condition. This research presents a new perspective to define the Malaysian financial condition by constructing three financial-segment-based indices. These segments are utilized in the FCI constructed by Bank Negara Malaysia (BNM) in 2017 that acted as one summary index. Following Badrudin and Abu Bakar (2017), this research employed the same twelve variables used in BNM's FCI to compute three financial-segment-based indices for this research. These Malaysian financial segments are the banking system (BANK), the foreign exchange market (FOREX), and the capital market (CAP). A drop in the index signifies potential pressure, while an increasing positive index implies easing in the condition of the financial segment. The inclusion of US balance sheet size as the external determinant investigates the impacts of the US UMP's actual operation on Malaysian financial condition, instead of the commonly practiced assessment by event studies via the LSAPs announcements or the conventional fed rate. 
The graph in Figure 1 shows the author-computed indices with labeled episodes of GFC and US QE programs. Overall, three indices of respective financial segments, i.e. banking system (BANK), foreign exchange markets (FOREX), and capital markets (CAP) showed volatile trends. GFC crashed the CAP index the most, compared to BANK and FOREX. There is no surprise, given the stock prices plunged a total of 517 points in the end-2008 from early 2008 where international businesses withdrew trades from Malaysia (Lim \& Goh, 2010; Tey et al., 2018). The impact of capital flight reflected potential stress in the FOREX index within the same timeframe. In contrast, the BANK index showed a comparatively modest sign of stress. After the US rolled out QE1, the CAP index boosted. In that timeframe, Malaysia portrayed stronger growth than the US, drawing more funds from the AEs including the US (Singh, 2014). Generally, QE3's implementation showed the mildest influence on the BANK, FOREX, and the CAP.

Figure 1: Indices of Financial Components, GFC and US Quantitative Easing

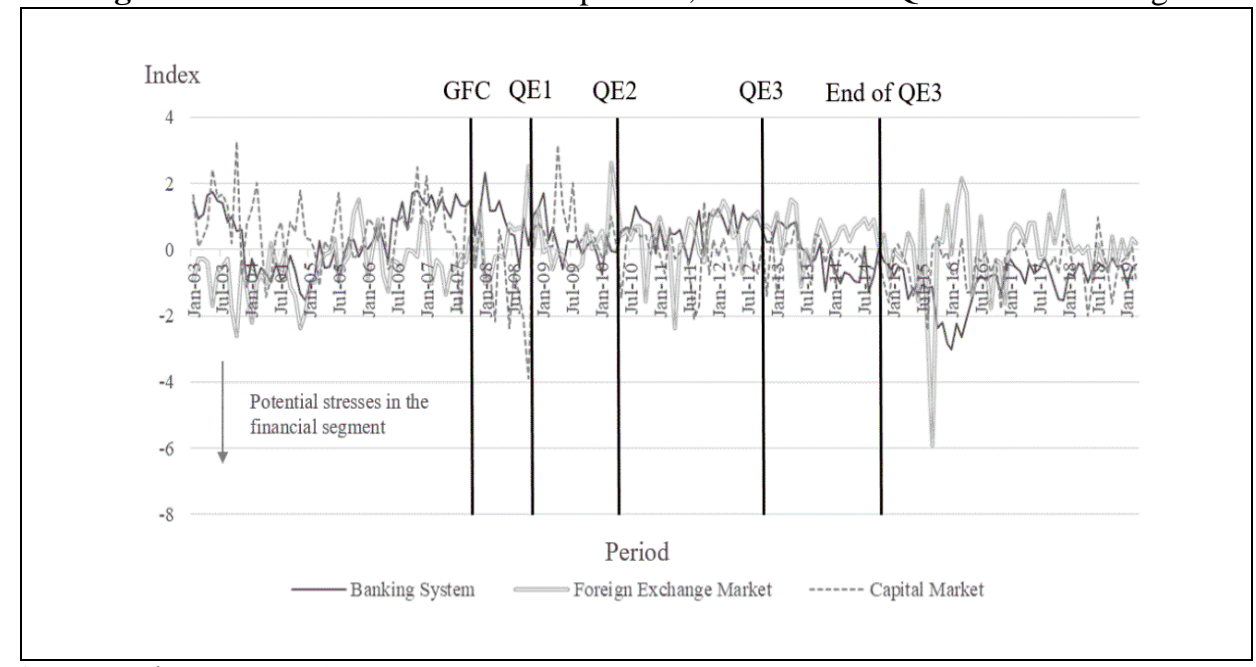

Source: Author's computation.

These graphical observations glance on the influence of US balance sheet size alterations over the Malaysian financial condition by observing the responses of each financial segment separately. The research intends to investigate the association between US balance sheet size and Malaysian financial condition in the long-run via the ARDL bound tests by Pesaran, Shin, and Smith (2001). The findings provide empirical evidence for the following research questions. Firstly, is there any valid association between the US balance sheet size and the financial condition in Malaysia in the long-run? Secondly, if such an association between the US balance sheet size and the financial condition in Malaysia is proven to be valid, what is its levels of effect? The research explores the long-run association concerning the US balance sheet size alteration and the Malaysian financial condition.

The research computed three financial-segment-based indices, informing the Malaysian financial condition in general. These indices include segments of the banking system, the foreign exchange, and capital market. The author-computed indices are assessed and they present improved performance on the explanatory power over the Malaysian economy. Finally, the research verified 
the long-run association between Malaysian financial condition and US balance sheet size, whereby the strongest influence is shown on the Malaysian banking system.

The research composes five sections. Section 2 reviews previous studies. The following section illustrates the utilized methodology, while Section 4 depicts the findings of the analysis. The final chapter provides a conclusion, also proposes policy implications and future recommendations.

\section{LITERATURE REVIEW}

\subsection{Financial Condition Index}

The policymakers' interest in the surveillance tool on the financial condition has doubled since the outburst of GFC (Badrudin \& Abu Bakar, 2017; Debuque-Gonzales \& Gochoco-Bautista, 2013; Hatzius et al., 2010). A tool like FCI earns its prominence for its ability to inform the general financial condition, taking the different financial segments within the system into account.

Over the decades, studies are developed on the FCI construction, ranging from AEs to EMEs. Researchers and major financial institutions across borders have developed their own FCI, from the US, selected European countries to Asian countries (Angelopoulou et al., 2014; Brave \& Butters, 2011; Debuque-Gonzales \& Gochoco-Bautista, 2017; Hatzius et al., 2010; Wacker, Lodge, \& Nicoletti, 2014). Some examples of well-established FCIs are Citi FCI and Bloomberg FCI (Hatzius et al., 2010). Hatzius et al. (2010) constructed a US FCI using 45 financial indicators via the Principal Component Approach (PCA). The study indicates the importance of financial condition to the policymakers and market participants, given its intermediary role to alter macroeconomic behavior. As of the end-2009, the US FCI estimation showed signs of stress owing to the US's credit condition. Besides, Koong, Law, and Ibrahim (2017) constructed a Malaysian financial stability index using 15 variables via the Dynamic Factor Model (DFM) to assess the synchronizing level between credit growth and financial stability. The study offered evidence on the increase in business credit tends to challenge Malaysia's financial stability.

Principal Component Approach (PCA) is one of the most commonly-practiced alternatives for FCI construction. For instance, the FCIs estimated by Federal Banks of Kansas City and Deutsche Bank (Hatzius et al., 2010; Osorio, Pongsaparn, \& Unsal, 2011). Its reputation grows given it derives information from a range of financial indicators into an unobserved factor that captures the comovement of the included/observed financial variables (Badrudin \& Abu Bakar, 2017). The PCA can identify the common factors that absorb the maximum common variation in the array of the included variables (Debuque-Gonzales \& Gochoco-Bautista, 2017). In 2017, Bank Negara Malaysia (BNM) computed Malaysian FCI via PCA (Badrudin \& Abu Bakar, 2017). The selected indicators for its FCI computation were commonly employed in prior literature, hence they were able to represent each financial segment within the system.

Instead of constructing a summary index like Badrudin and Abu Bakar (2017), this research computes three separate financial-segment-based indices particularly the indices for the banking system, foreign exchange, and capital markets. These indices or computed factors capture the maximum co-movement within the included financial variables. The unobserved common factor is important to be included in the model, for it allows improvement of the knowledge on the banking segment than solely including observed factors within the model (Bernoth \& Pick, 2011). 
The former can seize the common variation of an array of variables and it acts as an unobserved parameter.

The research continues to assess the explanatory power of three computed segment-based indices over the Malaysian economic growth, following Vonen (2011). Later, the research proceeds to identify the impact of US UMP on Malaysian financial condition. The linkage to the US is partially motivated by Debuque-Gonzales and Gochoco-Bautista (2017). The study depicted substantial influence from the US monetary decision to eight Asian economies including Malaysia, proven by the strong co-movement among Asian FCIs and their highly similar monetary conduct. Such finding is unsurprising, given majority economies, including Malaysia, anchored their currencies to the US's.

\subsection{The Influences of US UMP on the EMEs}

Chen et al., (2016) implied the US MP spillover effects are relatively more evident on the EMEs than AEs in general, even diverse results shown on EMEs. Punzi and Chantapacdepong (2017) suggested the UMP stance in the AEs tends to be reacted with accommodative MP by central banks in the Asia-Pacific region. Spillover effects of the US's UMP led to volatile capital flows, strengthening currency, and escalating asset prices in the EMEs (Punzi \& Chantapacdepong, 2017). The easing of the US's monetary stance drove portfolio funds to the EMEs, hence the EMEs inclined to react with accommodative MP conduct (Anaya, Hachula, \& Offermanns, 2017). The implemented US UMP substantially influenced the financial condition at altering levels, albeit identifying its ultimate influence on the real economy and inflation is trickier (Borio \& Zabai, 2018).

The US's monetary conduct portrayed substantial spillover influences on EMEs' financial and economic conditions (Bhattarai, Chatterjee, \& Park, 2017). A nation's descending economic condition appears to be relatively sensitive to the US's MP changes. When the US practices contractionary MP measures, generally the EMEs tend to raise their policy rate. The increase in the sovereign spread is spotted, alongside declining equity prices, and depreciating the nominal exchange rate. Bowman, Londono, and Sapriza (2015) shared a similar tone, suggesting the US's MP changes significantly influenced EMEs' asset prices, particularly the sovereign yields. The evident fluctuation was noticed during the Fed's UMP announcement.

The surging portfolio funds from the US to EMEs led by the Fed's UMP implementation since the dawn of GFC (Kiendrebeogo, 2016). The paper also suggested the nations with better mobility in their exchange rate regime, robust fiscal and current account status and flexible capital movement tend to have the upper hand when the exit of US's UMP measure took place. The LSAP significantly influenced the EMEs' financial condition, particularly the exchange rates, capital inflows, and equity prices (Tillmann, 2016). The US's LSAP boosts liquidity in the EMEs, contributing to rising asset prices, appreciating currency, and narrowing bond spreads. The LSAP's actual operation proved a relatively noteworthy impact than the LSAP's announcements (Fratzscher, Lo Duca, \& Straub, 2012). Ahmed and Zlate (2014), shedding light on the actual LSAPs operation than the announcements, suggested an important role played by the US UMP decision in the determination of the capital flows movement to the EMEs. 


\section{METHODOLOGY}

\subsection{Construction of Indices for Financial Condition in Malaysia}

The research employs twelve financial indicators to compute the financial-segment-based indices via Principal Components Approach (PCA) using the STATA software. PCA allows the indicators to "express as it is", given that PCA derives the common movement from the involved financial indicators. The financial variables may be conveyed as a common component that comprises factor loading, a factor with an error term that is unrelated to $F_{t}$ and uncorrelated across the variables (Wacker et al., 2014). Equation (1) formally addresses the expression:

$$
x_{i t}=\lambda_{i}{ }^{\prime} F_{t}+e_{t}
$$

Where $x_{i t}$ signifies the $i$-the financial variable at time $t, \lambda_{i}$ represents the factor loading for the $i$ the financial variable, $F_{t}$ signifies the common variation of the financial indicators at time $t$, and $e_{t}$ denotes the distinctive disturbance term. Equation (1) is substituted with the factor for respective financial segments as shown in Equations (2-4):

$$
\begin{gathered}
x_{i t}=\lambda_{i}{ }^{\prime} B A N K_{t}+e_{t} \\
x_{i t}=\lambda_{i}{ }^{\prime} \text { FOREX }_{t}+e_{t} \\
x_{i t}=\lambda_{i}{ }^{\prime} C A P_{t}+e_{t}
\end{gathered}
$$

Where BANK denotes the first principal components of banking sector credit spread, retail credit spread, and money supply M3; FOREX denotes the first principal component that seizes the common variation between the variables of REER, exchange rate volatility and international reserves; CAP denotes the first principal components that seize the co-movement extracted from the set of indicators, specifically the short-term and long-term yields, sovereign spread, KLCI index, KLCI volatility, and market capitalization.

Table 1 lists all of the involved financial indicators which are transformed based on the requirement, i.e. first-difference or the logarithm of first-difference. These transformed indicators series are standardized, that being said, the series will have a zero mean and standard deviation of 1 . Such computation is conducted to avoid domination during the PCA estimation, given alteration in $x$ 's measurement unit will result in deviations in the principal component. Conventionally, the minimization of quadratic gaps between the indicator, $x_{i t}$ and the common factor $\lambda_{i}{ }^{\prime} F_{t}$ for all $N$ series of financial indicators over the timeframe $T$ allows the decomposition of common components into the factor loading, $\lambda_{i}$ and the factor, $F_{t}$. The aforementioned minimization is denoted by Equation (5):

$$
\min \sum_{i=1}^{N} \sum_{t=1}^{T}\left(x_{i t}-\lambda_{i}{ }^{\prime} F_{t}\right)^{2}
$$

The computation through Ordinary Least Square (OLS) is direct and allows for broad implementation (Wacker et al., 2014). In this research, the estimation process will only pursue the 
first principal component as a representation of three domestic indices, namely BANK, FOREX, and CAP, after computing via PCA, and $N$ series of factors will be estimated. Generally, BANK, FOREX, and CAP are the weighted average over the $N$ series of financial indicators, $x$ where the factor loadings $\lambda_{i}$ is comprised of all derived weights. The first principal component will be used for the continuation of the estimation process to describe the maximum co-movement of all included financial variables, $x$.

\subsection{In-sample Regression of the Computed Indices}

The ability of computed indices to spot Malaysia's major economic events (represented by real GDP growth) is examined using in-sample regressions. This assessment is the only estimation step that uses quarterly data, due to the nature of real GDP growth (Vonen, 2011). It includes 65 quarterly observations ranging from 2003:Q1 till 2019:Q1. Equations (6-9) denote the regression models:

$$
\begin{array}{cc}
R G D P G_{t+h}=\beta_{0}+\beta_{1} R G D P G_{t}+\varepsilon_{t+1} \quad(h=1,2) \\
R G D P G_{t+h}=\beta_{0}+\beta_{1} R G D P G_{t}+\beta_{2} B_{A N K_{t}+\varepsilon_{t+1}} \quad(h=1,2) \\
R G D P G_{t+h}=\beta_{0}+\beta_{1} R G D P G_{t}+\beta_{2} F O R E X_{t}+\varepsilon_{t+1} & (h=1,2) \\
R G D P G_{t+h}=\beta_{0}+\beta_{1} R G D P G_{t}+\beta_{2} C A P_{t}+\varepsilon_{t+1} & (h=1,2)
\end{array}
$$

where the $R G D P G_{t}$ indicates the growth of Malaysian real GDP; $h$ is the forecast horizon; $\beta_{0}$ depicts the constant; $\beta_{1}$, and $\beta_{2}$ signifies the respective coefficients; $B A N K_{t}$ represents the banking system index; FOREX $X_{t}$ denotes the foreign exchange sector index; $C A P_{t}$ signifies the capital market index and the $\varepsilon_{t}$ describes the error term. The quarterly RGDPG is regressed on one lag of itself and a constant to consider its autoregressive part. Such a model provides a simple benchmark for comparison.

Later, an index i.e. BANK FOREX or CAP is included in the benchmark model. The indices are lagged accordingly to explain the respective quarterly observation of RGDPG. Finally, the Rsquared and the p-value of each model with the respective index is compared with the benchmark autoregressive model. $\mathrm{R}^{2}$ illustrates the explanatory power of independent variables over the variation in RGDPG in varying horizons, while the p-value displays the model significance. This identifies the significance of each index inclusion in explaining the Malaysian RGDPG.

\subsection{Autoregressive Distributed Lag (ARDL) Bounds Test Approach}

Following Pesaran et al., (2001), the ARDL bound test procedure inspects the validity of long-run association among the involved external and domestic indicators. This research prefers the ARDL bounds test approach, considering the mixed integration shown in the dataset after unit roots tests are performed. The long-run association is identified when F-statistics outperform the upper bound critical value (Nkoro \& Uko, 2016). The domestic indicators comprise three computed financialsegment-based indices of Malaysia, i.e. the banking system (BANK), foreign exchange market (FOREX), and capital market (CAP). The external indicator is the total assets of all Federal Reserve banks (USTA), representing the US balance sheet size. Natural logarithm transformation 
is performed on USTA for scale compression. The models were prepared for the bound testing approach, as shown in Equations (10-12).

$$
\begin{aligned}
& \triangle B A N K_{t}=\beta_{0}+\sum \beta_{1} \Delta B A N K_{t-i}+\sum \beta_{2} \Delta F O R E X_{t-i} \\
& +\sum \beta_{3} \Delta C A P_{t-i}+\sum \beta_{4} \Delta \ln U S T A_{t-i}+\alpha_{1} F O R E X_{t-1}+\alpha_{2} C A P_{t-1} \\
& +\alpha_{3} \ln U S T A_{t-1}+\varepsilon_{t} \\
& \triangle F O R E X_{t}=\beta_{0}+\sum \beta_{1} \Delta F O R E X_{t-i}+\sum \beta_{2} \Delta B A N K_{t-i} \\
& +\sum \beta_{3} \Delta C A P_{t-i}+\sum \beta_{4} \Delta \operatorname{lnUST} A_{t-i}+\alpha_{1} B A N K_{t-1}+\alpha_{2} C A P_{t-1} \\
& +\alpha_{3} \ln U S T A_{t-1}+\varepsilon_{t} \\
& \Delta C A P_{t}=\beta_{0}+\sum \beta_{1} \Delta C A P_{t-i}+\sum \beta_{2} \Delta B A N K_{t-i}+\sum \beta_{3} \Delta F O R E X_{t-i}+\sum \beta_{4} \Delta \ln U S T A_{t-i} \\
& +\alpha_{1} \text { BANK }_{t-1}+\alpha_{2} \text { FOREX }_{t-1}+\alpha_{3} \operatorname{lnUSTA_{t-1}}+\varepsilon_{t}
\end{aligned}
$$

Where $\beta_{0}$ indicates the intercept coefficient of the established equation; $\beta_{1}, \beta_{2}$ and $\beta_{3}$ signify the respective slope parameter; and $\varepsilon_{t}$ represents the disturbance term in the equation. The F-statistics for each model in the bound tests is extracted to compare with the bound critical values. Once Fstatistics surpass the critical value at the upper bound, the presence of cointegration within the model is validated. Later, Equations (10-12) are expanded into Equations (13-15) under the error correction model (ECM). :

$$
\begin{aligned}
& \Delta B A N K_{t}=\beta_{0}+\sum \beta_{1} \Delta B A N K_{t-i}+\sum \beta_{2} \Delta F O R E X_{t-i} \\
& +\sum \beta_{3} \Delta C A P_{t-i}+\sum \beta_{4} \Delta \ln U S T A_{t-i}+\lambda E C_{t-1}+\varepsilon_{t} \\
& \triangle F O R E X_{t}=\beta_{0}+\sum \beta_{1} \Delta F O R E X_{t-i}+\sum \beta_{2} \Delta B A N K_{t-i} \\
& +\sum \beta_{3} \Delta C A P_{t-i}+\sum \beta_{4} \Delta \ln U S T A_{t-i}+\lambda E C_{t-1}+\varepsilon_{t} \\
& \Delta C A P_{t}=\beta_{0}+\sum \beta_{1} \Delta C A P_{t-i}+\sum \beta_{2} \Delta B A N K_{t-i}+\sum \beta_{3} \Delta F O R E X_{t-i}+\sum \beta_{4} \Delta \text { lnUSTA } A_{t-i} \\
& +\gamma E C_{t-1}+\varepsilon_{t}
\end{aligned}
$$

Where the error correction term's coefficient, $E C_{t-1}$ is being represented by $\gamma$. It reflects the speed of adjustment to attempt correction of disequilibrium in the long-run within the model.

\subsection{Data}

Table 1 describes the Malaysian financial indicators used in three computed financial-segmentbased indices, alongside the required transformation and data sources. Starting from December 2002 till March 2019, the sample accumulates 196 monthly observations. The volatility series for the exchange rate and KLCI are computed using the GARCH $(1,1)$ model. The first index, the Malaysian banking system index (BANK) is computed using three variables based on Table 1. Money supply informs the money market condition while the interest rate differentials generally exhibit perceived market risk. The second index, foreign exchange market index (FOREX) consists of three variables, referring to Table 1. The REER depicts the relative process of currency, the exchange rate volatility indicates the potential financial stress, while international reserves display 
BNM's capability to maneuver financial concerns. The third index, capital market index (CAP) comprises six indicators, representing the bond and equity market. The term yields exhibit the cost of borrowing, the sovereign spread reflects the cross-border financial development. KLCI measures stock market performance, its volatility reveals market risk and investors' doubt, while market capitalization displays the market's well-being.

Table 1: Description of Selected Financial Indicators for Index Construction

\begin{tabular}{|c|c|c|}
\hline Index & Variable & Transformation \\
\hline \multirow{3}{*}{$\begin{array}{c}\text { Banking system } \\
\text { (BANK) }\end{array}$} & Banking sector credit spread a (KLIBOR3M-MTB3M) & 1 \\
\hline & Retail credit spread a (ALR-MGS10Y) & 1 \\
\hline & Broad Money, M3 a & 3,4 \\
\hline \multirow{3}{*}{$\begin{array}{c}\text { Foreign } \\
\text { exchange } \\
\text { (FOREX) }\end{array}$} & REER $^{\mathrm{c}}$ & 3 \\
\hline & Exchange rate volatility ${ }^{d}$ & 1 \\
\hline & International reserves ${ }^{a}$ & 3 \\
\hline \multirow{6}{*}{$\begin{array}{l}\text { Capital market } \\
\text { (CAP) }\end{array}$} & 3-Months Malaysian Treasury Bill ${ }^{\text {a }}$ & 2 \\
\hline & 10-Years Malaysian Government Securities ${ }^{\text {a }}$ & 2 \\
\hline & Sovereign spread a, b (MGS10Y - USTN10Y) & 1 \\
\hline & $\mathrm{KLCI}^{\mathrm{a}}$ & 3 \\
\hline & KLCI volatility ${ }^{d}$ & 1 \\
\hline & Market capitalization $^{\mathrm{a}}$ & 3 \\
\hline
\end{tabular}

Notes: Data sources - ${ }^{\mathrm{a}}$ Bank Negara Malaysia (BNM), ${ }^{\mathrm{b}}$ Federal Reserve Economic Data (FRED), ${ }^{\mathrm{c}}$ International Financial Statistics (IFS), 'A Author's computation; Transformation - Level (1), First-difference (2), Log first-difference (3), Seasonally-adjusted (4)

Table 2 outlines the author-computed Malaysian financial-segment-based indices and one US indicator. These four variables will be used to validate the research's main aim - the long-run association between domestic and external determinants via ARDL bounds test procedure. The sample period ranges from January 2003 till March 2019, presenting a total of 195 monthly observations. Three indices represent the banking system, foreign exchange, and capital market respectively. These standardized indices have zero mean and unit variance. This ensures the "zero" represents the particular financial component is functioning at its historical average, while the -1 (+1) indicates potential tension (easing) than normal by one standard deviation for the particular financial component. To represent the US balance sheet size, the natural log of US total assets of Fed banks (lnUSTA) is included.

Table 2: Description of Computed Indices and US Total Assets

\begin{tabular}{ccc}
\hline \hline Variable & Frequency & Transformation \\
\hline Banking system (BANK) $^{\mathrm{a}}$ & Monthly & 1 \\
Foreign exchange market (FOREX) $^{\text {a }}$ & Monthly & 1 \\
Capital market (CAP) $^{\mathrm{a}}$ & Monthly & 1 \\
Total Assets of All Federal Reserve Banks (lnUSTA) $^{\mathrm{b}}$ & Monthly & 2 \\
\hline \hline
\end{tabular}

Notes: Data Sources - ${ }^{a}$ Author's computation; ${ }^{\mathrm{b}}$ Federal Reserve Economic Data (FRED); Transformation - Level (1), Natural $\log (2)$ 


\subsection{Estimation Procedure}

Three financial-segment-based indices are computed using STATA software via PCA. Next, the dataset including newly-constructed indices and the size of the US balance sheet is being prepared via an excel spreadsheet to ease the following empirical analysis conducts using EViews 11. First, the explanatory performance of the constructed indices over the Malaysian economy is examined. Later, the external and domestic indicators, i.e. the computed Malaysian indices (BANK, FOREX, and CAP), and the US total assets (lnUSTA) are tested using ADF and PP stationarity tests. Different orders of integration among the indicators in the conduct of the unit root tests progresses the estimation process to the ARDL bound test approach. Lag 2 is preferred under the Akaike Information Criterion (AIC), given it shows minimum value among available criteria. The stability of each model is assessed using five diagnostic tests to prevent the spurious outcome.

\subsection{Descriptive Statistics}

\section{RESULTS AND DISCUSSION}

Figure 2 depicts the plotted graphs using the series of three Malaysian financial-segment-based indices and a US-originated indicator, particularly the segments of the banking system (BANK), foreign exchange market (FOREX), and capital market (CAP), and US total asset of all Fed Banks (lnUSTA). The series covers the period from January 2003 to March 2019.

BANK demonstrated potential stresses at end-2015, which was identical to FOREX. In 2015, scenarios like collapsing global oil prices, the GST implementation, and the domestic political scandals, depressed investors' sentiment towards the Malaysian economy outlook. Hence, Malaysia's currency value plummeted, surfacing as one of the worst-performing currencies globally (Tey et al., 2018). The household consumption momentarily dipped, slowing down the businesses and economic progress. In 2008, CAP exhibited visible pressure, considering a severe GFC spillover impact. At the period, the performance of Malaysia's equity prices crashed, entailing the economic slump (Tey et al., 2018). For the external determinant, lnUSTA boosted at the end2008, followed with gradual increments from then until end-2014. The end-2008 elevation in InUSTA indicated the Fed's first implementation of the QE program upon the ineffectiveness of conventional MP, involving rounds of large-scale purchases of securities (LSAPs) (Neely \& Bhattarai, 2016).

Figure 2: Trends of BANK, FOREX, CAP, and lnUSTA

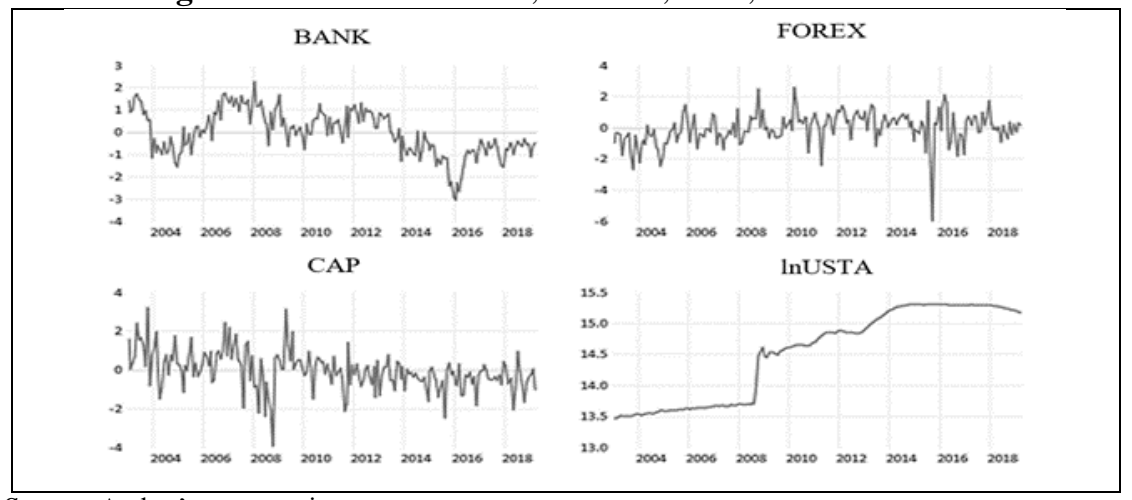

Source: Author's computation. 


\subsection{Factor Loadings for the Computed Indices}

Figure 3 portrays the factor loading for each indicator used in the construction of indices, i.e. BANK, FOREX, and CAP respectively. The estimated coefficient of the factor loading, $\lambda_{i}$, indicates the weightage of financial indicator in the index (Debuque-Gonzales \& Gochoco-Bautista, 2013). It depicts the pairwise correlation between the factor and each of the included indicators. Generally, a positive factor loading implies a positive association between the indicator and the corresponding index (represented by the first principal component (PC1)) in this research. PC1 also refers to the 1-dimensional factor for its ability to capture the maximum proportion of common variation within the included financial indicators (Koong et al., 2017; Vonen, 2011). The observed indicators with loadings exceeding 0.60 are briefly identified as the main forces behind the comovement captured by the index. The main forces that contribute to the movement in the BANK are the banking sector and retail credit spread. Mainly the REER and international reserve drive FOREX. The KLCI and market capitalization are CAP's key momentum.

Figure 3: Principal Component Loadings of Computed Indices

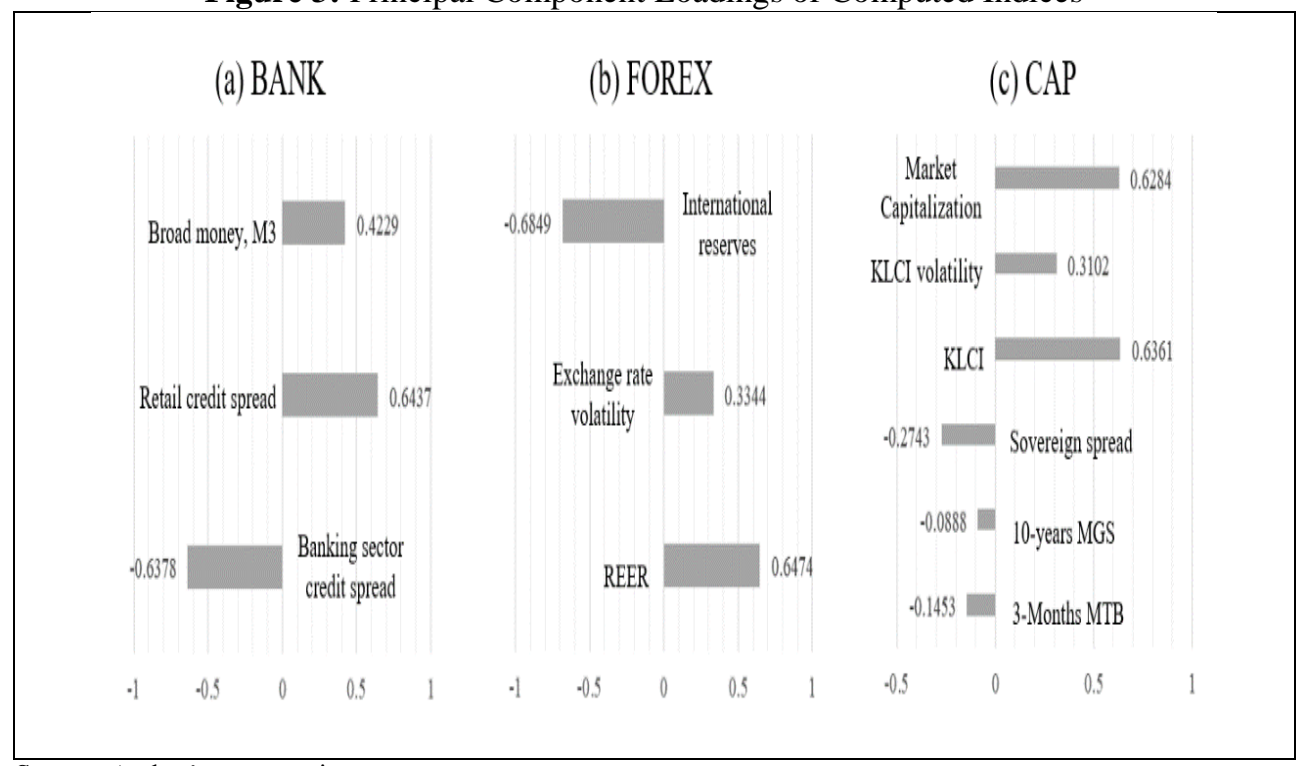

Source: Author's computation

\subsection{In-sample Regressions using the Computed Indices}

Table 3 illustrates the indices' explanatory power, i.e. BANK, FOREX, and CAP over the Malaysian real GDP growth. Overall, the inclusion of the computed indices shows improvements in the explanatory power over the Malaysian real GDP growth. The strongest impact is being observed on the regression model with the addition of the CAP index at both horizons. All models portray significance at 5\% level. It implies the indices' ability to capture the major economic episodes in Malaysia. 
Table 3: $\mathrm{R}^{2}$ and P-Values for In-Sample Regression Models

\begin{tabular}{ccccc}
\hline \hline \multirow{2}{*}{ Model } & \multicolumn{2}{c}{$\mathbf{h}=\mathbf{1}$} & \multicolumn{2}{c}{$\mathbf{h}=\mathbf{2}$} \\
\cline { 2 - 5 } & R-squared & p-value & R-squared & p-value \\
\hline Benchmark model $^{\mathrm{a}}$ & 0.608 & 0.000 & 0.111 & 0.008 \\
Addition of BANK Index $^{\mathrm{b}}$ & 0.613 & 0.000 & 0.114 & 0.027 \\
Addition of FOREX Index $^{\mathrm{c}}$ & 0.624 & 0.000 & 0.135 & 0.013 \\
Addition of CAP Index $^{\mathrm{d}}$ & 0.638 & 0.000 & 0.284 & 0.000 \\
\hline \hline
\end{tabular}

Notes: ${ }^{a}$ Refer to Equation (6); ${ }^{b}$ Refer to Equation (7); ${ }^{c}$ Refer to Equation (8); ${ }^{\text {d }}$ Refer to Equation (9).

\section{Lag Order Selection}

Table 4 shows the estimated ARDL model specification for M1, M2, and M3 under the Akaike Information Criterion (AIC). $\mathrm{Lag}=2$ is selected under the AIC, considering the lowest value is shown $(\beta=3.263)$ among the tested lags.

Table 4: Specification of Estimated ARDL Models

\begin{tabular}{ccc}
\hline \hline Model & Equation & Selected Model \\
\hline M1 & $F(B A N K \mid F O R E X, C A P, \ln U S T A)$ & ARDL $(2,2,0,0)$ \\
M2 & $F(F O R E X \mid B A N K, C A P, \ln U S T A)$ & ARDL $(1,0,2,1)$ \\
M3 & $F(C A P \mid B A N K, F O R E X, \ln U S T A)$ & ARDL $(1,1,1,2)$ \\
\hline \hline
\end{tabular}

\subsection{Stationarity Tests}

Table 5 describes the outcomes of the ADF and PP stationarity tests. Both tests guide the conduct of the ARDL bounds test procedure, considering if the variables show integration level at $\mathrm{I}(0)$ or I(1). The result demonstrates mixed outcome for the studied variables at level while showing significant stationarity at first difference. To conclude, the stationarity of all indicators is present at $\mathrm{I}(0)$ and $\mathrm{I}(1)$, suggesting compatibility with ARDL estimation.

Table 5: Test Results for Stationarity

\begin{tabular}{ccccc}
\hline \hline & \multicolumn{2}{c}{ Augmented Dickey-Fuller (ADF) Test } & \multicolumn{2}{c}{ Phillips-Perron (PP) Test } \\
\cline { 2 - 5 } Variable & \multicolumn{4}{c}{ Level, I(0) } \\
\cline { 2 - 5 } & Intercept & $\begin{array}{c}\text { Intercept and } \\
\text { Trend }\end{array}$ & Intercept & $\begin{array}{c}\text { Intercept and } \\
\text { Trend }\end{array}$ \\
\cline { 2 - 5 } & $-2.365(2)$ & $-2.631(2)$ & $-3.858(5)^{* * *}$ & $-4.682(6)^{* * *}$ \\
BANK & $-5.464(2)^{* * *}$ & $-10.008(0)^{* * *}$ & $-9.944(7)^{* * *}$ & $-10.248(6)^{* * *}$ \\
FOREX & $-5.174(2)^{* * *}$ & $-11.450(0)^{* * *}$ & $-10.794(7)^{* * *}$ & $-11.688(5)^{* * *}$ \\
CAP & $-1.202(6)$ & $-1.007(6)$ & $-1.168(2)$ & $-0.989(2)$ \\
lnUSTA & \multicolumn{5}{c}{ First Difference, I(1) } \\
\hline Variable & $-13.878(1)^{* * *}$ & $-13.844(1)^{* * *}$ & $-24.395(7)^{* * * *}$ & $-24.351(7)^{* * *}$ \\
\hline BANK & $-8.468(6)^{* * *}$ & $-6.622(13)^{* * *}$ & $-39.395(15)^{* * *}$ & $-39.314(15)^{* * *}$ \\
FOREX & $-9.277(5)^{* * *}$ & $-9.265(5)^{* * *}$ & $-78.882(48)^{* * *}$ & $-78.384(48)^{* * *}$ \\
CAP & $-5.437(5)^{* * *}$ & $-5.514(5)^{* * *}$ & $-8.062(24)^{* * * *}$ & $-7.984(25)^{* * * *}$ \\
lnUSTA &
\end{tabular}

Notes: The table depicts the t-statistic of the unit root test, where *** (**)* represents $1 \%, 5 \%$, and $10 \%$ significance level correspondingly. The parentheses contain values that represent the lag length (Newey-West bandwidth using the Bartlett kernel) for the $\mathrm{ADF}(\mathrm{PP})$ test. 


\subsection{Stability Tests}

Table 6 shows the assessment of the models' stability via five diagnostic tests to examine the common assumptions of ARDL regression. To prevent the rejection of normality assumptions caused by limited extreme values, the outliers in the regression residuals of the model are diagnosed for dummies selection (Brooks, 2008). The residuals of all models portray normal distribution, given that the p-values of the Jarque-Bera statistics are greater than 0.05 in the conduct of the normality test. The autocorrelation result displays the absence of serial correlation in all models, considering all models' Chi-squares surpass 0.05 .

The result of White's test indicates the absence of heteroscedasticity given their prob. F exceeds 0.05, implying evident homoscedasticity. The outcome for Ramsey RESET test shows all p-values exceeding 0.05 , reflecting the absence of obvious non-linearity in all models. Figure 4 demonstrates the CUSUM and CUSUMQ test results. All graphs show the middle lines lying within the range of two straight lines that act as the upper and lower limits, therefore all models are stable at 5\% significance level. In short, the stability of all models is validated.

Table 6: Results of the Diagnostic Tests

\begin{tabular}{|c|c|c|c|c|}
\hline \multicolumn{2}{|c|}{ Model } & M1 & M2 & M3 \\
\hline \multicolumn{2}{|c|}{ Dummies in the model } & \multirow{2}{*}{$\begin{array}{c}\text { D0312; D0801 } \\
\mathbf{M 1}\end{array}$} & \multirow{2}{*}{$\begin{array}{c}\text { D1509; D1104; } \\
\text { D1508; D1003; } \\
\text { D0712; D1609 }\end{array}$} & \multirow{2}{*}{$\begin{array}{c}\text { D0806; D0708 } \\
\text { D0803; D0904 } \\
\text { M3 }\end{array}$} \\
\hline Diagnostic Tests & Statistics & & & \\
\hline \multirow{2}{*}{ Normality Test } & Jarque-Bera & 1.049 & 4.684 & 4.128 \\
\hline & Probability & 0.592 & 0.096 & 0.127 \\
\hline \multirow{2}{*}{ Autocorrelation Test } & F-statistic & 2.402 & 0.939 & 0.383 \\
\hline & Prob. Chi-Square & 0.083 & 0.363 & 0.661 \\
\hline \multirow{2}{*}{$\begin{array}{c}\text { Heteroscedasticity } \\
\text { Test: White }\end{array}$} & F-statistic & 0.620 & 1.348 & 0.929 \\
\hline & Prob. F & 0.779 & 0.189 & 0.520 \\
\hline \multirow{2}{*}{ Ramsey RESET Test } & F-statistic & 1.348 & 0.340 & 2.151 \\
\hline & Prob. F & 0.247 & 0.561 & 0.144 \\
\hline
\end{tabular}

Figure 4: Results of CUSUM and CUSUMQ Tests

Model M1: $F(B A N K \mid F O R E X, C A P, \ln U S T A)$

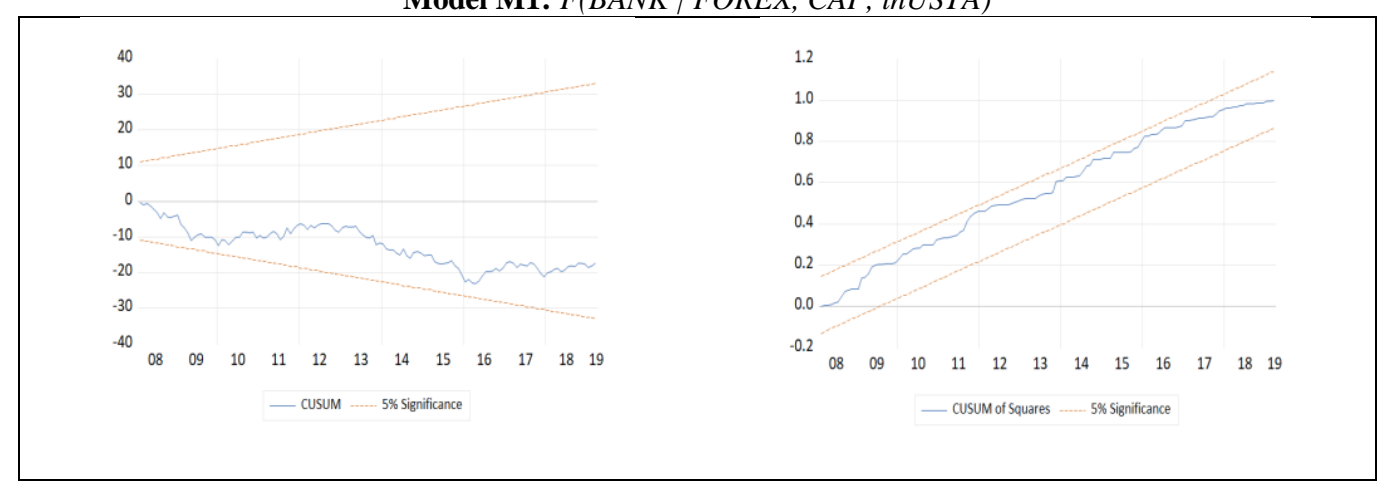


Model M2: $F(F O R E X \mid B A N K, C A P, \ln U S T A)$

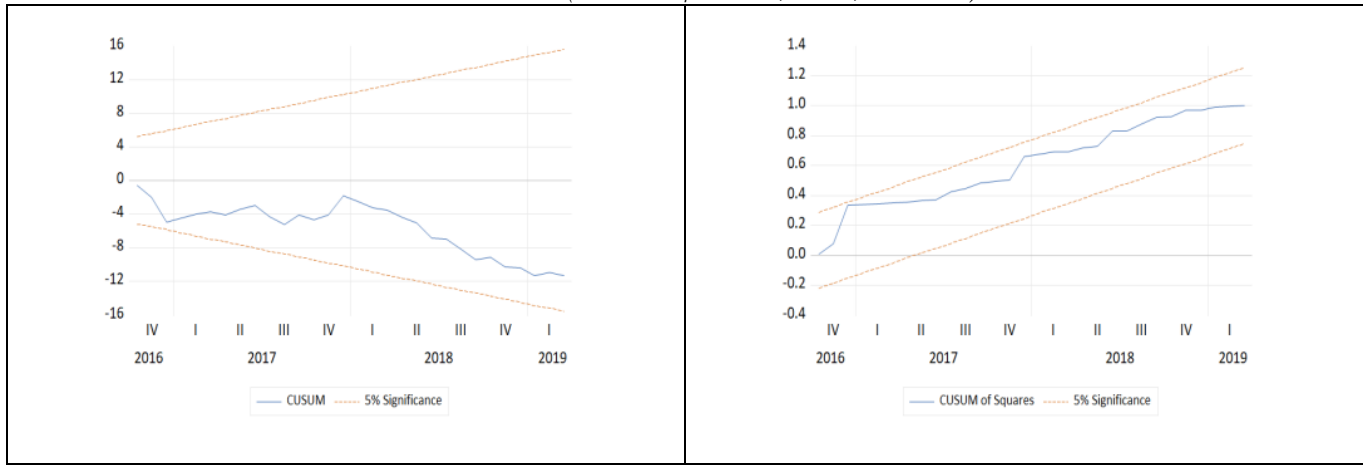

Model M3: $F(C A P \mid B A N K, F O R E X, \ln U S T A)$

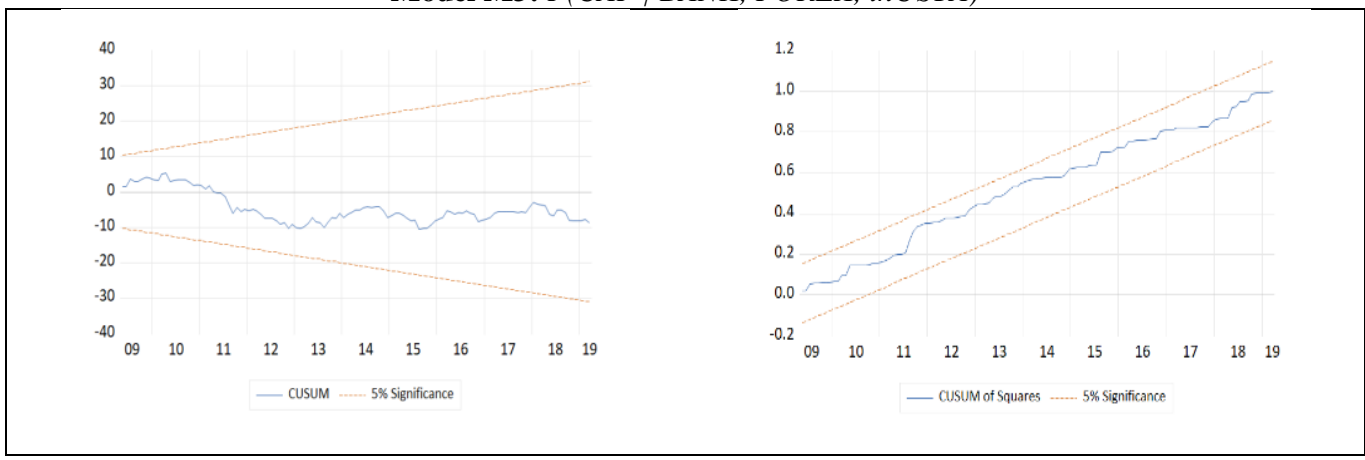

Source: Author's computation.

\subsection{Bounds Test Approach}

Table 7 presents the results for bounds test procedure. All models' F-statistics are contrasted with the bound critical values. The values of model M2 and M3 have exceeded the I(1) at $1 \%$ significance level, while the value of model M1 exceeds at 2.5\% significance level. In summary, the cointegration is absent in all models, hence validating the long-run association in all models.

Table 7: Results of Bound Test Approach

\begin{tabular}{|c|c|c|c|}
\hline Model & Equation & \multicolumn{2}{|c|}{ F-Statistic } \\
\hline M1 & $F(B A N K \mid F O R E X, C A P, \ln U S T A)$ & \multicolumn{2}{|c|}{$4.936 * * *$} \\
\hline M2 & F(FOREX $\mid$ BANK, CAP, InUSTA) & \multicolumn{2}{|c|}{$47.362 * * * *$} \\
\hline M3 & \begin{tabular}{l|l}
$F(C A P$ & $B A N K, F O R E X, \ln U S T A)$ \\
\end{tabular} & \multicolumn{2}{|c|}{$48.353 * * * *$} \\
\hline \multicolumn{4}{|c|}{$\begin{array}{c}\text { Bounds test critical values } \\
\text { (Case III. Unrestricted intercept and no trend) }\end{array}$} \\
\hline & Level of Significance & $\mathbf{I}(\mathbf{0})$ & $\mathbf{I}(\mathbf{1})$ \\
\hline & $10 \%$ & 2.72 & 3.77 \\
\hline & $5 \%$ & 3.23 & 4.35 \\
\hline & $2.5 \%$ & 3.69 & 4.89 \\
\hline & $1 \%$ & 4.29 & 5.61 \\
\hline
\end{tabular}

Notes: $* * * *(* * *) * *(*)$ represents significant at $1 \%, 2.5 \%, 5 \%$ and $10 \%$ level correspondingly. 


\subsection{Error Correction Model (ECM)}

Table 8 presents the coefficients of the cointegration equation for models M1, M2, and M3. The outcomes show negative values and statistical significance at $1 \%$. Such results verify the stability of the adjustment process to correct the long-run disequilibrium in all models. Among the speed of adjustment shown by all of the illustrated models, model M1 shows the lowest speed of $18.00 \%$, while model M3 depicts the highest speed of $89.9 \%$ towards long-run equilibrium. In essence, the long-run equilibrium associations for all three models are verified.

Table 8: Results of Error Correction Model

\begin{tabular}{clcc}
\hline \hline Model & Equation & CointEq(-1) Coefficient & Probability \\
\hline M1 & $F(B A N K \mid F O R E X, C A P, \ln U S T A)$ & $-0.180^{* * *}$ & 0.0000 \\
M2 & $F(F O R E X \mid B A N K, C A P, \ln U S T A)$ & $-0.785^{* * *}$ & 0.0000 \\
M3 & $F(C A P \mid B A N K, F O R E X, \ln U S T A)$ & $-0.899^{* * *}$ & 0.0000 \\
\hline \hline
\end{tabular}

Notes: *** represents significance at $1 \%$ level.

\subsection{Long-run Coefficients}

Table 9 depicts the projected coefficients for model M1, M2, and M3 in the long-run. Based on Table 9, all of the independent variables in model M1 show statistical significance at the $1 \%$ level with the dependent variable, BANK, except for CAP which shows no sign of significance with a coefficient of 0.098. Looking at the significant association with BANK, the positive relationship is shown in the association with FOREX, while the negative relationship is shown in the association with InUSTA. When the foreign exchange market index increases by $1 \%$, the banking system index will increase by $0.839 \%$. When there is a $1 \%$ contraction in the US balance sheet size, there will be a $0.954 \%$ increase in the banking system index. All of the explanatory variables in model M2 show an insignificant association with the dependent variable, FOREX, except for lnUSTA which shows statistical significance at the $1 \%$ level. Among the insignificant relationships with FOREX, a negative tie with a coefficient of 0.174 is being depicted by CAP, while BANK exhibits a positive tie with a coefficient of 0.093. In contrast, the significant and positive association with FOREX is depicted by lnUSTA. That being said, when there is a $1 \%$ decrease in the US balance sheet size, there will be a decrease in the index of the foreign exchange market by $0.497 \%$. For model M3, all of the independent variables shows statistical significance when associating with the dependent variable CAP at $1 \%$ significance level, except for FOREX, showing its significance at $10 \%$ level. The negative association with CAP is found in FOREX and lnUSTA. A 1\% decline in the foreign exchange market index (the US balance sheet size) increase the capital market index by $0.153 \%$ $(0.406 \%)$. In contrast, a positive association with CAP is portrayed by BANK, implying that a $1 \%$ rise in the banking system index will contribute to the rise of the capital market index by $0.218 \%$.

The result also indicated that CAP has no significant explanatory power to BANK and FOREX, but it serves as a relatively great response variable. Such characteristics of CAP contradict with FOREX, which has significant explanatory power to BANK and CAP but it has comparably less significant when it comes to being a response variable. Observing the association among the domestic financial segments, positive interactions are identified in the association between BANK and FOREX, and the association between CAP and BANK. In contrast, the association between CAP and FOREX depicts negative interaction. When the banking system index increases, the index of the foreign exchange market and the capital market tends to decline. On the contrary, the easing 
of capital market conditions will result in the tightening of foreign exchange markets, and vice versa. In summary, the strongest level of impact among the variables in all models is displayed by the negative association between BANK and lnUSTA, with a coefficient of 0.954 at $1 \%$ significance level. Through the result, the research finds that the US-originated financial indicator, InUSTA exerts highly significant impacts on all three domestic indices - BANK, FOREX, and CAP at varying strength of effects. The strongest effect is spotted on the BANK, followed by FOREX and CAP. The specified long-run models for models M1, M2, and M3 are shown in Equations (16-18).

Long-run model for model M1:

$$
\widehat{B A N K}_{t}=13.819+0.839 F O R E X_{t}^{* * *}+0.098 C A P_{t}-0.954 \ln U S T A_{t}^{* * *}
$$

Long-run model for model M2:

$$
F \widehat{O R E} X_{t}=-7.203+0.093 B A N K_{t}-0.174 C A P_{t}+0.497 \ln U S T A_{t}^{* * *}
$$

Long-run model for model M3:

$$
\widehat{C A P}_{t}=5.975+0.218 B A N K_{t}^{* * *}-0.153 F O R E X_{t}^{*}-0.406 \ln U S T A_{t}^{* * *}
$$

Table 9: Estimated Long-run Coefficients for Model M1, M2 and M3

\begin{tabular}{cccccc}
\hline \hline Model & Variable & Coefficient & Std. Error & t-Statistics & Prob. \\
\hline & $\mathrm{C}$ & $13.819^{* * *}$ & 4.590 & 3.011 & 0.003 \\
M1 & FOREX & $0.839^{* * *}$ & 0.319 & 2.631 & 0.009 \\
(Response Variable: BANK) & CAP & 0.098 & 0.212 & 0.463 & 0.644 \\
& lnUSTA & $-0.954^{* * *}$ & 0.315 & -3.027 & 0.003 \\
\hline \multirow{2}{*}{ M2 } & $\mathrm{C}$ & $-7.203^{* * *}$ & 1.764 & -4.083 & 0.000 \\
(Response Variable: FOREX) & BANK & 0.093 & 0.078 & 1.191 & 0.235 \\
& CAP & -0.174 & 0.116 & -1.506 & 0.134 \\
& lnUSTA & $0.497^{* * *}$ & 0.121 & 4.107 & 0.000 \\
\hline & $\mathrm{C}$ & $5.975^{* * *}$ & 1.619 & 3.691 & 0.000 \\
M3 & BANK & $0.218^{* * *}$ & 0.078 & 2.791 & 0.006 \\
(Response Variable: CAP) & FOREX & $-0.153^{*}$ & 0.085 & -1.785 & 0.076 \\
& lnUSTA & $-0.406^{* * *}$ & 0.111 & -3.652 & 0.000 \\
\hline \hline
\end{tabular}

Notes: $*(* *) * * *$ denotes $10 \%, 5 \%$ and $1 \%$ significance level.

\section{CONCLUSION}

The dawn of GFC has underlined the importance of determining the US spillover impacts, also the emphasis of nurturing a sound financial condition for its significant tie between the MP transmission and ultimately, the macroeconomic behavior. This research analyses the determinants of the Malaysian financial condition, both domestically and externally. In this research, the conduct of the ARDL bounds test procedure allows assessment on the association between the Malaysian financial condition and the size of US balance sheet (lnUSTA) in the long-run.

As a representation of the financial condition in Malaysia, three indices that comprise different segments of the financial system are being computed in this research, namely the banking system (BANK), the foreign exchange market (FOREX), and the capital market (CAP). The author- 
computed indices are examined and they present improved performance on the explanatory power over the Malaysian economy. This finding is aligned with Vonen (2011), suggesting that the inclusion of principal components in the in-sample regression models shows significant improvements, although their $\mathrm{R}^{2}$ was relatively smaller compared to the finding of this research. Looking to the outcome for the long-run association between the external and domestic determinants, it is interesting to notice that the levels of impact that are driven by lnUSTA in all of the tested models show comparably higher strengths than the other included domestic indicators, ranging from $0.406 \%$ to $0.954 \%$. The most substantial effect from the US balance sheet size is observed on BANK, followed by FOREX and CAP. Departing from such findings, the lnUSTA has a very significant influence over the Malaysian financial condition in the long-run, indicating that the alteration of the US balance sheet size could not be merely dismissed to allow a better assessment over the domestic financial environment.

Greater interdependence between nations in the era of globalization has inevitably exposed the nations to more risks stemming from the global financial condition. Singh (2014) has pointed out that such a situation has amplified on Malaysian financial condition after the AEs adopted the UMP in their policy regime, causing substantial increment in the global liquidity. The available room for global risk mitigation has become increasingly constrained for the Malaysian policymakers to decide a policy stance when it comes to the issues related to economic stability. Based on the empirical results, the increment in the US balance sheet size will significantly underpin the potential stresses in the condition of the Malaysian banking system and capital market, while eases the condition of the Malaysian foreign exchange market. Such significance is in the same vein with the findings of Chua, Endut, Khadri, \& Sim (2013). Their study has discovered substantial effects from the AEs' implementation of QE plans towards the exchange rates, monetary conditions, and asset prices of a group of EMEs, comprising Malaysia. The finding on the US effects the Malaysian financial condition is also related to the study of Chen et al., (2016) as it has presented evidence on the international spillover originating in the US MP tends to significantly ignite instability in the economy and the financial market. The most significant impact from the alteration of the US balance sheet size is shown in the condition of the Malaysian banking system, which is composed of interest rate differentials and money supply. It has found support in the findings by Miyakoshi, Shimada, and Li (2017). The paper points out that the interest rate differentials are one of the financial indicators that are more prone to the effects originated from the alteration in MP.

Chen et al., (2016) suggest that the US monetary decision's response to the cross-border spillover is likely to be proportional to its level of effectiveness. Hence, it is necessary to develop stronger resilience in the Malaysian banking system by monitoring the money supply, and improving the quality of the financial instruments i.e. short and long-term government securities. Such action is suggested due to the condition of the banking system being more prone to potential stresses when the US balance sheet size is under expansion. To sustain more growth and stability, it is necessary to pinpoint the need to be well-equipped with strengthened fundamentals. To nurture flexibility in the economic fundamentals, Malaysia should implement proactive action to tackle the potential fragility of the financial system, better competitiveness by deepening research and development, and human capital development as found by Georgiadis (2016) as one of the efforts of curbing fragility towards the alteration in US MP is by nurturing financial development in the domestic market. 


\section{ACKNOWLEDGMENT}

Funding for this research is originated from the Fundamental Research Grant Scheme (FRGS) FRG0458-2017 provided by the Ministry of Education, Malaysia.

\section{REFERENCES}

Ahmed, S., \& Zlate, A. (2014). Capital flows to emerging market economies: A brave new world? Journal of International Money and Finance, 48, 221-248. doi: 10.1016/j.jimonfin.2014.05.015

Anaya, P., Hachula, M., \& Offermanns, C. J. (2017). Spillovers of U.S. unconventional monetary policy to emerging markets: The role of capital flows. Journal of International Money and Finance, 73, 275-295. doi:10.1016/j.jimonfin.2017.02.008

Angelopoulou, E., Balfoussia, H., \& Gibson, H. D. (2014). Building a financial conditions index for the euro area and selected euro area countries: What does it tell us about the crisis? Economic Modelling, 38, 392-403. doi: https://doi.org/10.1016/j.econmod.2014.01.013

Badrudin, I., \& Abu Bakar, Z.-F. (2017). Financial condition index for Malaysia. Bank Negara Malaysia Quarterly Bulletin Third Quarter 2017, 37-42.

Bauer, M. D., \& Neely, C. J. (2014). International channels of the Fed's unconventional monetary policy. Journal of International Money and Finance, 44, 24-46. doi: 10.1016/j.jimonfin.2013.12.007

Bernoth, K., \& Pick, A. (2011). Forecasting the fragility of the banking and insurance sectors. Journal of Banking and Finance, 35(4), 807-818. doi: 10.1016/j.jbankfin.2010.10.024

Bhattarai, S., Chatterjee, A., \& Park, W. Y. (2017). US monetary policy spillovers. HKIMR Working Paper No 17/2017.

Borio, C., \& Zabai, A. (2018). Unconventional monetary policies: a re-appraisal. BIS Working Papers No 570. doi: https://www.bis.org/publ/work570.pdf

Bowman, D., Londono, J. M., \& Sapriza, H. (2015). U.S. unconventional monetary policy and transmission to emerging market economies. Journal of International Money and Finance, 55(1109), 27-59. doi: 10.1016/j.jimonfin.2015.02.016

Brave, S., \& Butters, R. A. (2011). Monitoring financial stability: A financial conditions index approach. Economic Perspectives, 35(1), 22-43.

Brooks, C. (2008). Introductory Econometrics for Finance. Cambridge: Cambridge University Press. doi: https://doi.org/10.1017/CBO9780511841644

Chen, Q., Filardo, A., He, D., \& Zhu, F. (2016). Financial crisis, US unconventional monetary policy and international spillovers. Journal of International Money and Finance, 67, 6281. doi: 10.1016/j.jimonfin.2015.06.011

Chua, W. S., Endut, N., Khadri, N., \& Sim, W. H. (2013). Global monetary easing : Spillovers and lines of defence for EMEs. BNM Working Paper Series WP3/2013. Retrieved from http://www.bnm.gov.my/files/working_papers/sim_et_al_FINAL_261213_JKK.pdf.

Debuque-Gonzales, M., \& Gochoco-Bautista, M. S. (2013). Financial condition indexes for Asian economies. SSRN Electronic Journal, 1-61. doi: 10.2139/ssrn.2221736

Debuque-Gonzales, M., \& Gochoco-Bautista, M. S. (2017). Financial condition indexes and monetary policy in Asia. Asian Economic Papers, 16(2), 83-117. doi: 10.1162/ASEP_a_00522

Fratzscher, M., Lo Duca, M., \& Straub, R. (2012). A global monetary tsunami ? On the spillovers 
of US Quantitative Easing. CEPR Discussion Paper No. 9195.

Georgiadis, G. (2016). Determinants of global spillovers from US monetary policy. Journal of International Money and Finance, 67, 41-61. doi: 10.1016/j.jimonfin.2015.06.010

Hatzius, J., Hooper, P., Mishkin, F., Schoenholtz, K. L., \& Watson, M. W. (2010). Financial condition indexes: A fresh look after the financial crisis. NBER Working Paper No. 16150. Cambridge, Ma: National Bureau of Economic Research.

Hofmann, B., \& Takats, E. (2015). International Monetary Spillovers. BIS Quarterly Review, 105118. Retrieved from https://papers.ssrn.com/sol3/Delivery.cfm/SSRN_ID2661596_code 1109023.pdf?abstractid=2661596\&mirid=1

Kiendrebeogo, Y. (2016). Unconventional monetary policy and capital flows. Economic Modelling, 54, 412-424. doi:10.1016/j.econmod.2016.01.008

Koong, S. S., Law, S. H., \& Ibrahim, M. H. (2017). Credit expansion and financial stability in Malaysia. Economic Modelling, 61, 339-350. doi: 10.1016/j.econmod.2016.10.013

Lim, M.-H., \& Goh, S. K. (2010). The Impact of Global Financial Crisis: The case of Malaysia. Malaysia: Third World Network Publications.

Miyakoshi, T., Shimada, J., \& Li, K. (2017). The dynamic effects of quantitative easing on stock price_Evidence from Asian emerging markets, 2001-2016. International Review of Economics and Finance, 49(March), 548-567. doi: 10.1016/j.iref.2017.03.002

Neely, C. J., \& Bhattarai, S. (2016). A survey of the empirical literature on U.S. unconventional monetary policy. Federal Reserve Bank of St. Louis Working Paper No 2016-021E. St. Louis, MO, USA. doi:10.20955/wp.2016.021

Nkoro, E., \& Uko, A. K. (2016). ARDL cointegration technique: Application and interpretation. Journal of Statistical and Econometric Methods, 5(4), 63-91. doi:10.1002/jae.616

Osorio, C., Pongsaparn, R., \& Unsal, D. F. (2011). A quantitative assessment of financial conditions in Asia. IMF Working Paper No. WP/11/170.

Pesaran, M. H., Shin, Y., \& Smith, R. J. (2001). Bounds testing approaches to the analysis of level relationships. Journal of Applied Econometrics, 16(3), 289-326. doi: 10.1002/jae.616

Punzi, M. T., \& Chantapacdepong, P. (2017). Spillover effects of Unconventional Monetary Policy in Asia and the Pacific. ADBI Working Paper Series No. 630. Tokyo: Asian Development Bank Institute.

Singh, S. (2014). Spillovers from global monetary conditions : recent experience and policy responses in Malaysia. BIS Papers No. 78. Malaysia: Central Bank of Malaysia.

Tey, H. C., Baharudin, A. H., \& Fuad, H. A. (2018). Malaysian Economy: Unlocking Growth, Sustaining Equity. Shah Alam, Selangor, Malaysia: Oxford Fajar Sdn. Bhd.

Tillmann, P. (2016). Unconventional monetary policy and the spillovers to emerging markets. Journal of International Money and Finance, 66, 136-156.

Vonen, N. H. (2011). A financial conditions index for Norway. Staff Memo No. 07/2011. Norway: Norges Bank.

Wacker, K. M., Lodge, D., \& Nicoletti, G. (2014). Measuring financial condition in major NonEuro area economies. European Central Bank Working Paper Series No. 1743. 